\title{
Characterization of quinoa (Chenopodium quinoa) fermented by Rhizopus oligosporus and its bioactive properties
}

\author{
Jaewon Hur ${ }^{1}$, Thi Thanh Hanh Nguyen², Namhyeon Park², Jeesoo Kim ${ }^{1}$ and Doman Kim 1,2,3*
}

\begin{abstract}
Quinoa is a pseudocereal that contains high quality protein, minerals, vitamins, polyphenols, and phytosterols. In this study, quinoa was fermented by Rhizopus oligosporus (R. oligosporus) up to 5 days and the functional compounds ( $L$-carnitine, GABA, vanillic acid and gallic acid) were analyzed by LC/MS. The amounts of L-carnitine and GABA were $0.13 \mathrm{mg} / \mathrm{kg}$ and $540 \mathrm{mg} / \mathrm{kg}$ for nonfermented quinoa (NF), $3.15 \mathrm{mg} / \mathrm{kg}$ and $1040 \mathrm{mg} / \mathrm{kg}$ for fermented quinoa at 3 days (3F), and $1.54 \mathrm{mg} / \mathrm{kg}$ and $810 \mathrm{mg} / \mathrm{kg}$ for fermented quinoa at 5 days (5F). The vanillic acid and gallic acid were 1.3 and $0.1 \mathrm{mg} / \mathrm{kg}$ for NF, 1.55 and $2.37 \mathrm{mg} / \mathrm{kg}$ for $3 F$, and 1.83 and $0.84 \mathrm{mg} / \mathrm{kg}$ for $5 F$, respectively. Total phenolic contents and total flavonoids contents were $41 \mathrm{mg}$ gallic acid (GAE)/ $\mathrm{kg}$ and $13 \mathrm{mg}$ quercetin equivalent (QE)/kg for NF, $74 \mathrm{mg} \mathrm{GAE} / \mathrm{kg}$ and $16 \mathrm{mg}$ QE/ $/ \mathrm{kg}$ for $3 F$, and $80 \mathrm{mg} \mathrm{GAE} / \mathrm{kg}$ and $19 \mathrm{mg}$ QE/kg for $5 F$, respectively. Antioxidant activity $\left(\mathrm{SC}_{50}\right.$ ) was $3.6 \mathrm{mg} / \mathrm{mL}$ for $\mathrm{NF}, 3.4 \mathrm{mg} / \mathrm{mL}$ for $3 \mathrm{~F}$, and $2.3 \mathrm{mg} / \mathrm{mL}$ for $5 \mathrm{~F}$. Nitric oxide production on RAW264.7 macrophages of fermented quinoa revealed $29 \%$ and $56 \%$ inhibition of nitric oxide production for NF and $5 F$, respectively. Therefore, fermented quinoa can be used as a healthy and valuable food product.
\end{abstract}

Keywords: Anti-inflammatory activity, Antioxidant activity, Fermentation, L-Carnitine, Quinoa, Rhizopus oligosporus

\section{Introduction}

Quinoa (Chenopodium quinoa) has been widely cultivated in South America for 5000-7000 years (VegaGálvez et al. 2010). It has high nutritional properties and contents of antioxidant compounds; essential amino acids, vitamins, minerals, and unsaturated fatty acids (Carciochi et al. 2016). Lysine and methionine contents are high in quinoa, deficient in many legumes and rice, and also can be a precursor of L-carnitine synthesis (Koeth et al. 2013). L-carnitine is synthesized from lysine and methionine, serving an essential function in transportation of fatty acids into the mitochondrial compartment for $\beta$-oxidation and subsequent energy production (Bremer 1983). L-carnitine is abundant in red meat $(5977 \mathrm{mg} / \mathrm{kg}$ beef) but in lesser amounts in crops $(0.4 \mathrm{mg} / \mathrm{kg}$ wheat seed), and plants $(2.9 \mathrm{mg} / \mathrm{kg}$ tomatoes,

\footnotetext{
*Correspondence: kimdm@snu.ac.kr

${ }^{1}$ Graduate School of International Agricultural Technology, Seoul

National University, Pyeongchang 25354, Republic of Korea

Full list of author information is available at the end of the article
}

$0.8 \mathrm{mg} / \mathrm{kg}$ avocado) (Steiber et al. 2004). In addition, $\mathrm{L}$-carnitine is an antioxidant compound that can prevent oxidative stress and regulates cellular respiration by nitric oxide (Brown 1999). As an antioxidant role of L-carnitine, mainly three enzymes (glutathione peroxidase, catalase, and superoxide dismutase) are prevented from peroxidative damage (Kalaiselvi and Panneerselvam 1998).

Rhizopus oligosporus (R. oligosporus) is a dominant fungus in special fermented soybean products like Indonesia teampeh. During the fermentation by $R$. oligosporus, the macromolecules were hydrolyzed by enzymes and coupled with the metabolism of the corresponding hydrolytic products to changes in the biochemical composition of food substrates (deReu et al. 1997; Handoyo and Morita 2006). Fermented soybean with $R$. oligosporus showed increase amounts of $\gamma$-aminobutyric acid (GABA), one of main fermented products from synthesizing from glutamate by glutamate decarboxylase (Dhakal et al. 2012; Handoyo and Morita 2006). In our previous study, R. oligosporus was used to produce L-carnitine and GABA in buckwheat by fermentation with no additional nutrients, 
and feed for chickens to gain high L-carnitine content in eggs (Park et al. 2016). The quinoa fermentation by using $R$. oligosporus have been reported (Matsuo 2005, 2006). However, these studies only focus on antioxidant activity of fermented quinoa. And there was no report for the improvement of L-carnitine and GABA in fermented quinoa as well as its biological and biochemical studies. In this regard, we fermented quinoa with $R$. oligosporus DK1 to improve the quality of the food regarding the enhancement of L-carnitine, GABA, phenolic acid compounds, antioxidant and anti-inflammatory effects. White quinoa was selected for this study because it contains more antioxidative compounds than those of red and black quinoa (Masayo and Watanabe 2010).

\section{Materials and methods}

\section{Microbial strain and culture condition}

Rhizopus microspores var. oligosporus was obtained from our previous study (Park et al. 2016) and deposited as KCCM 11948P (Korean Culture Center of Microorganisms, Seoul, Korea). It was maintained on Potato Dextrose Agar (PDA, Difco, USA) plates.

\section{Preparation of fermented quinoa}

Rhizopus oligosporus was cultured on PDA medium at $30{ }^{\circ} \mathrm{C}$ for 3 days to prepare spores (Park et al. 2016). White quinoa was purchased from KtFood (Seoul, Korea). $150 \mathrm{~g}$ quinoa was soaked in $150 \mathrm{~mL}$ water for $12 \mathrm{~h}$ and steamed for $20 \mathrm{~min}$ at $121^{\circ} \mathrm{C}$. Fermentation was conducted by inoculating $1 \times 10^{4}$ spores/g steamed quinoa at $30{ }^{\circ} \mathrm{C}$ for $3-5$ days. Fermented quinoa was lyophilized at -10 to $0{ }^{\circ} \mathrm{C}$ under $20 \mathrm{~Pa}$ (Tokyo Rikakikai Co., Tokyo, Japan) for further study.

\section{Sample extraction}

$300 \mathrm{~g}$ lyophilized quinoa was extracted with $1 \mathrm{~L}$ of ethanol for $1 \mathrm{~h}$ at $28^{\circ} \mathrm{C}$ in the shaking incubator and repeated seven times, then filtered using filter paper (8 micron, $11 \mathrm{~cm}$ ) (Whatman LTD., Maidstone, England). Ethanol in the sample was removed by evaporation (Heidolph Instruments, Schwabach, Germany) with addition of $400 \mathrm{~mL}$ distilled water. The lipid layers from extracted sample were removed and the extracted sample were lyophilized for further study. Extraction yield was calculated as follows;

$$
\text { Yield }(\mathrm{g} / 100 \mathrm{~g}) \%=\frac{\text { extract mass }(\mathrm{g})}{\text { quinoa mass }(300 \mathrm{~g})} \times 100(\%)
$$

\section{Scanning electron microscopy image analyses}

Quinoa surfaces of sample prepared before and after fermentation were observed using a scanning electron microscope (SEM, TM 3030plus, Hitachi, Tokyo, Japan).
Whole grain images were taken at magnification of $\times 100$, $5.0 \mathrm{kV}$ of accelerate voltage in secondary electron (SE) mode. At magnification $\times 1.0 \mathrm{k}$, fungi hypha was removed and observed at $15 \mathrm{kV}$ of accelerate voltage in SE mode.

\section{Analyses of $\mathrm{L}$-carnitine and GABA}

LC/MS analysis was conducted by using the method as our previously described (Park et al. 2016). Samples were dissolved in water for analysis of L-carnitine or GABA. Samples were diluted with acetonitrile for L-carnitine and GABA, and all filtered using a $0.2 \mu \mathrm{m}$ membrane (Sartorius AG, Gottingen, Germany). A $1 \mu \mathrm{L}$ sample was injected into the LC/MS system (Waters, Milford, MA, USA); Waters Acquity H-Class system with Waters QDa detector, Waters Acquity UPLC BEH HILIC $1.7 \mu \mathrm{m}$, $2.1 \mathrm{~mm} \times 100 \mathrm{~mm}$ column. Solvent A was $15 \mathrm{mM}$ ammonium formate with $0.1 \%$ formic acid in distilled water and solvent $\mathrm{B}$ was $0.1 \%$ formic acid in acetonitrile. The temperature of column was maintained at $40{ }^{\circ} \mathrm{C}$. The following elution gradient was applied for L-carnitine and GABA analyses; $0-3 \mathrm{~min}, 10 \% \mathrm{~A} ; 3.1-5 \mathrm{~min}, 10-30 \% \mathrm{~A}$; 5.1-6 min, 30-60\% A; then a 4 min for equilibrium step. Electrospray ionization (ESI) was conducted with a positive with selective ion recording (SIR) (m/z 162 for L-carnitine and $\mathrm{m} / \mathrm{z} 104$ for GABA). Capillary energies were $1.5 \mathrm{kV}$. Cone voltage was $10 \mathrm{~V}$ for $\mathrm{L}$-carnitine and $5 \mathrm{~V}$ for GABA. Acetonitrile $(90 \%, v / v)$ was used as a blank. Calibration curves were prepared using the external standard method with L-carnitine concentrations ranged from 0.01 to $1 \mu \mathrm{g} / \mathrm{mL}$, GABA ranged from 0.1 to $10 \mu \mathrm{g} / \mathrm{mL}$. Linearity between concentrations of standards vs area was evaluated $\left(r^{2}>0.99\right)$.

\section{Analyses of phenolic acids}

LC/MS analysis was conducted by using the method as previously described (Park et al. 2016). Samples were dissolved in DMSO for vanillic acid, chlorogenic acid, or gallic acid as $10 \mathrm{mg} / \mathrm{mL}$. Samples were diluted with methanol for phenolic acids, and all filtered using a $0.2 \mu \mathrm{m}$ membrane. A $1 \mu \mathrm{L}$ sample was injected into the LC/MS system. Solvent A was distilled with water and solvent B was acetonitrile with $1 \mathrm{~mL}$ formic acid/L. The temperature of column was maintained at $40{ }^{\circ} \mathrm{C}$. The following elution gradient was applied for phenolic acids analyses; 0-0.5 min, $95 \% \mathrm{~A}$; $0.5-3 \mathrm{~min}, 95-70 \% \mathrm{~A}$; 3-5 $\min , 70-0 \% \mathrm{~A} ; 5-6 \mathrm{~min}, 0 \% \mathrm{~A}$; then a 4 min for equilibrium step. ESI was conducted with a negative with SIR (m/z 169 for gallic acid, $\mathrm{m} / \mathrm{z} 353$ for chlorogenic acid, and $\mathrm{m} / \mathrm{z} 167$ for vanillic acid). Capillary energy was $0.8 \mathrm{kV}$ for phenolic acids. Cone voltage was $10 \mathrm{~V}$ for phenolic acids and methanol was used as a blank. Calibration curves were prepared using the external standard method with phenolic acids concentration ranged from 0.1 to $10 \mu \mathrm{g} /$ 
$\mathrm{mL}$. Linearity between concentrations of standards vs area was evaluated $\left(r^{2}>0.99\right)$.

\section{Total phenolic contents analysis (TPC)}

The total phenolic contents were determined by Folin ciocalteu's method (Masayo and Watanabe 2010) with gallic acid as the standard (Sigma). $10 \mathrm{mg}$ quinoa or fermented quinoa extracted powder was dissolved in $1 \mathrm{~mL}$ water. Each $120 \mu \mathrm{L}$ of sample or gallic acid $(0-50 \mu \mathrm{g} / \mathrm{mL})$ was added into 96 wells plate and $15 \mu \mathrm{L}$ of Folin ciocalteu's reagent (Sigma) was mixed together for $3 \mathrm{~min}$ in dark condition. Then, $15 \mu \mathrm{L}$ of $10 \%(\mathrm{w} / \mathrm{v}) \mathrm{Na}_{2} \mathrm{CO}_{3}$ was added and reacted for $30 \mathrm{~min}$ in dark condition. The TPC were determined by spectrophotometry at $750 \mathrm{~nm}$ (SpectraMax M3, Molecular Devices, USA) and presented as gallic acid equivalent (GAE).

\section{Total flavonoid contents (TFC) analysis}

TFC was determined by aluminum chloride colorimetric method (Chang et al. 2002) with quercetin as the standard (Sigma). $20 \mathrm{mg}$ quinoa or fermented quinoa extracted powder was dissolved in $1 \mathrm{~mL}$ DMSO, and then fivefolds diluted in methanol to give final concentration as $1 \mathrm{mg} / \mathrm{mL}$ and volume of $2 \mathrm{~mL}$. Each sample or quercetin $(0-15 \mu \mathrm{g} / \mathrm{mL})$ was mixed with $100 \mu \mathrm{L}$ of $10 \%(\mathrm{w} / \mathrm{v}) \mathrm{AlCl}_{3}$ and $100 \mu \mathrm{L}$ of $0.1 \mathrm{mM} \mathrm{CH}_{3} \mathrm{CO}_{2} \mathrm{~K}$. TFC was determined by spectrophotometry at $415 \mathrm{~nm}$ using SpectraMax M3 and presented as quercetin equivalent $(\mathrm{QE})$.

\section{Determination of DPPH radical scavenging activity}

Antioxidant activities of quinoa or fermented quinoa were evaluated by 2,2-diphenyl-1-picrylhydrazyl (DPPH) radical scavenging method (Nguyen et al. 2015). Quinoa extracted powder were diluted in $70 \%$ ethanol and centrifuged at $13,572 \times g$ for $10 \mathrm{~min}$. Supernatants were reacted with $100 \mu \mathrm{M}$ DPPH (Sigma) in ethanol solution to give a final concentration of $0.2-7 \mathrm{mg}$ quinoa extract $/ \mathrm{mL}$, then, kept at room temperature for $30 \mathrm{~min}$ in darkness. Absorbance of each sample was measured at $517 \mathrm{~nm}$ on a microplate reader, SpectraMax M3. DPPH radical-scavenging activity was converted into percentage of antioxidant activity using the following equation (Choi et al. 2018a):

$$
\begin{aligned}
& \text { DPPH radcal }- \text { scavenging activity }(\%) \\
& =\frac{(\text { Absorbance of control }- \text { Absorbance of test sample) }}{\text { Absorbance of control }} \\
& \quad \times 100
\end{aligned}
$$

A linear regression curve was established to determine the amount of sample necessary to decrease $50 \%$ of the absorbance of DPPH ( $\mathrm{SC}_{50}$ value). All analyses were conducted in duplicate. Results were expressed as mean \pm standard error (SEM).

\section{Cell cytotoxicity tests}

RAW264.7 mouse macrophage cell line was purchased from Korean Cell Line Bank (Seoul, Korea) and cultured in Dulbecco's modified Eagle's medium (DMEM, Gendepot, USA) supplemented with $10 \%(\mathrm{v} / \mathrm{v})$ fetal bovine serum (FBS, Gendepot, USA), $100 \mathrm{U} / \mathrm{mL}$ penicillin and $100 \mu \mathrm{g} / \mathrm{mL}$ streptomycin (Invitrogen, USA) at $37^{\circ} \mathrm{C}$ in $5 \% \mathrm{CO}_{2}$ (Choi et al. 2018b; Maxwell et al. 2017). RAW264.7 macrophage cell was seeded on 96 wells plate at $2 \times 10^{4}$ cells/well and cultured for $48 \mathrm{~h}$. Cells were rinsed with phosphate-buffered saline (PBS) and then treated with quinoa or fermented quinoa extract in DMEM medium without Fetal bovine serum (FBS) ranging from 1.56 to $1600 \mu \mathrm{g} / \mathrm{mL}$ obtained by diluting quinoa or fermented quinoa extract with the culture medium. RAW 246.7 cells cultured in a medium without adding samples were used as controls. After $24 \mathrm{~h}$ at $37^{\circ} \mathrm{C}, 90 \mu \mathrm{L}$ of medium was mixed with $10 \mu \mathrm{L}$ of Ez-CyTox solution (Daeil Lab Service, Seoul, Korea) and then incubated at $37{ }^{\circ} \mathrm{C}$ for $1 \mathrm{~h}$. Absorbance was measured at $450 \mathrm{~nm}$ using SpectraMax M3. Percent viability was calculated as cell viability relative to the control.

\section{Measurement of nitric oxide production}

Nitric oxide production was determined as previously described method (Kim et al. 1999). RAW 264.7 cells were seeded to 96 wells plate at $2 \times 10^{4}$ cells/well and cultured at $37{ }^{\circ} \mathrm{C}$ for $48 \mathrm{~h}$. The sample treated with $1 \mu \mathrm{g}$ LPS/ $\mathrm{mL}$ and $100 \mu \mathrm{M}$ indomethacin was used as positive control. Cells were then treated with quinoa or fermented quinoa extract in DMSO ranging from 12.5 to $50 \mu \mathrm{g} / \mathrm{mL}$ without effects on cytotoxicity under testing, and cultured at $37{ }^{\circ} \mathrm{C}$ for $24 \mathrm{~h}$. Then, $80 \mu \mathrm{L}$ of culture supernatant was mixed with $80 \mu \mathrm{L}$ of Griess reagent containing $1 \%(\mathrm{w} / \mathrm{v})$ sulfanilamide in $5 \%(\mathrm{v} / \mathrm{v})$ phosphoric acid, and $0.1 \%(\mathrm{w} / \mathrm{v})$ naphthylethylenediamine, for $20 \mathrm{~min}$, and absorbance was measured at $540 \mathrm{~nm}$ using SpectraMax M3. The amount of nitrite in the sample was evaluated from a standard curve generated with a sodium nitrite standard curve $(0-500 \mu \mathrm{M}$ in cell culture medium).

\section{Statistical analysis}

Experimental results were statistically analyzed by t-test (IBM SPSS Statistics 22, IBM, USA). Values are presented as mean \pm standard error of the mean (SEM). Significant differences between the groups were evaluated and indicated by different lower-case letters $(\mathrm{p}<0.05$ and $\mathrm{p}<0.01)$. 


\section{Results}

\section{Scanning electron microscopic observation}

The general quinoa and degradation of quinoa after fermentation were observed by the SEM. Figure 1 shows the surface of general and fermented quinoa. General quinoa (Fig. 1a) was observed with smooth surface. Fermented quinoa (Fig. 1b, c) was covered by $R$. oligosporus and mycelium was observed on fermented quinoa. The washed off fermented quinoa (Fig. 1e, f) revealed surface degradation comparable to the general quinoa (Fig. 1d), and exposed starch granule.

\section{Ethanol extraction of fermented quinoa}

The extraction yields of NF, 3F, and 5F were $23.4 \%, 45.9 \%$, and $39.1 \%$, respectively. Among them, 3 days fermented quinoa showed highest extraction yield.

\section{Analyses of L-carnitine, GABA, and phenolic acids}

The L-carnitine content was enhanced from $0.13 \mathrm{mg} / \mathrm{kg}$ to 3.15 and $1.54 \mathrm{mg} / \mathrm{kg}$ of quinoa extracts at $3 \mathrm{~F}$ and $5 \mathrm{~F}$, respectively (Table 1 ). GABA was produced by the $R$. oligosporus fermentation, from $540 \mathrm{mg} / \mathrm{kg}$ to 1040 and
Table 1 L-carnitine, GABA and phenolic acids in regular and fermented quinoa

\begin{tabular}{llll}
\hline Group & NF & 3F & $\mathbf{5 F}$ \\
\hline L-carnitine (mg/kg of extracts) & 0.13 & $3.15 \pm 0.06^{* * *}$ & $1.54 \pm 0.06^{* *}$ \\
$\begin{array}{l}\text { GABA (mg/kg of extracts) } \\
\text { Phenolic acids }\end{array}$ & $540 \pm 3$ & $1040 \pm 10^{* *}$ & $810 \pm 3^{* *}$ \\
$\begin{array}{c}\text { Vanillic acid (mg/kg of } \\
\quad \text { extracts) }\end{array}$ & $1.3 \pm 0.04$ & $1.55 \pm 0.06^{* *}$ & $1.83 \pm 0.06^{* *}$ \\
$\begin{array}{c}\text { Gallic acid (mg/kg of extracts) } \\
\text { Chlorogenic acid (mg/kg of } \\
\text { extracts) }\end{array}$ & 0.01 & $2.37 \pm 0.08^{* *}$ & $0.84 \pm 0.02^{* *}$ \\
\hline
\end{tabular}

(NF non-fermented, $3 F 3$ days, $5 F 5$ days of fermented quinoa extracts); (NF vs $3 F$ and $5 F, * * p<0.01$ )

$810 \mathrm{mg} / \mathrm{kg}$ of quinoa extracts at $3 \mathrm{~F}$ and $5 \mathrm{~F}$, respectively (Table 1). Concentration of vanillic acids was increased during fermentation as $1.3,1.55$, and $1.83 \mathrm{mg} / \mathrm{kg}$ in NF, $3 \mathrm{~F}$, and $5 \mathrm{~F}$ extracts, respectively (Table 1 ). Concentration of gallic acid was $0.01,2.37$, and $0.84 \mathrm{mg} / \mathrm{kg}$ in NF, $3 \mathrm{~F}$, and $5 \mathrm{~F}$ extracts, respectively (Table 1 ). Chlorogenic acid was found $0.002 \mathrm{mg} / \mathrm{kg}$ for NF and $5 F$, but $0.03 \mathrm{mg} /$ $\mathrm{kg}$ was detected at $3 \mathrm{~F}$ extract (Table 1).
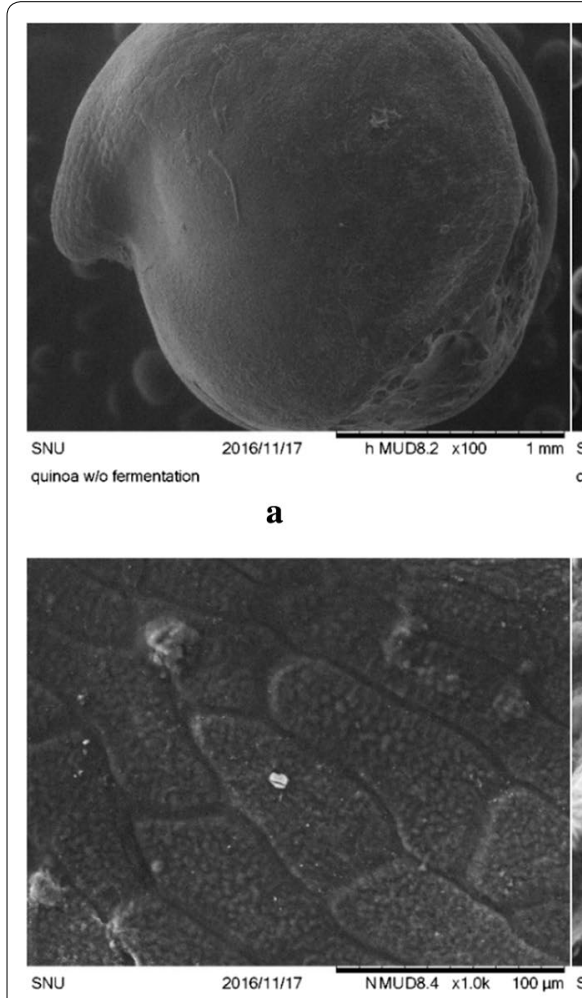

quinoa w/o fermentation

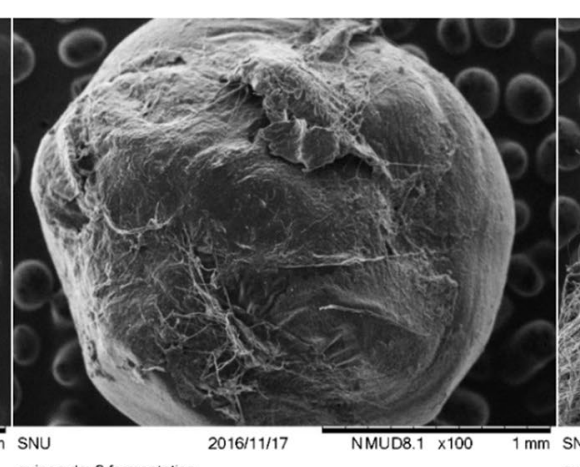

b

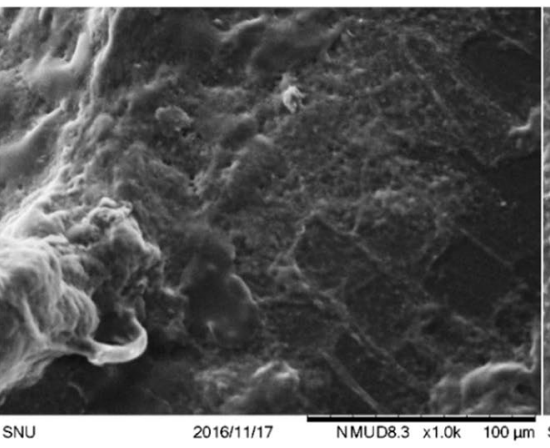

$\mathbf{e}$

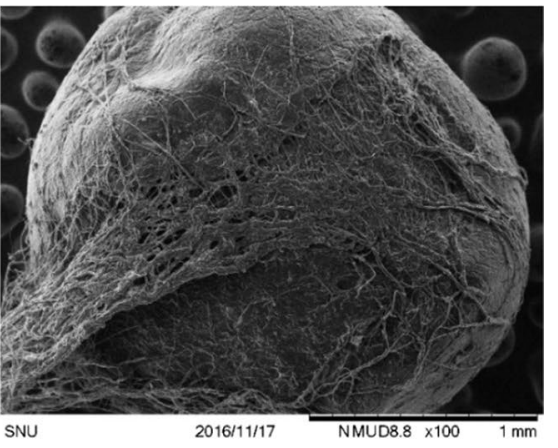

quinoa day 5 fermentation

c

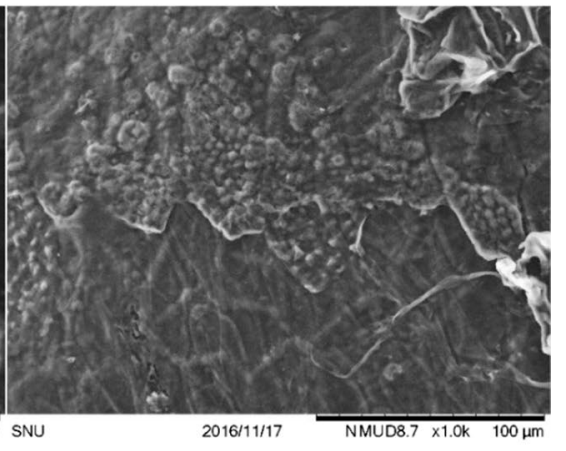

quinoa day 5 fermentation

f

Fig. 1 Scanning electron microscope of fermented quinoa. a NF, $\times 100 ; \mathbf{b} 3 F, \times 100 ; \mathbf{c} 5 F, \times 100 ; \mathbf{d} N F, \times 1000$; e hypha removed 3F, $\times 1000 ; \mathbf{f}$ hypha removed $5 F, \times 1000$. (NF Non-fermented, $3 F ; 3$ days, $5 F ; 5$ days of fermented quinoa extracts) 
Total phenol content, total flavonoid content, and antioxidant activity of quinoa

Antioxidant activity was mainly investigated based on analysis of TPC, TFC, or DPPH radical-scavenging activity of each sample. After fermentation, TPC was increased from $41 \mathrm{mg}$ GAE $/ \mathrm{kg}$ to 74 and $80 \mathrm{mg} \mathrm{GAE} /$ $\mathrm{kg}$ of quinoa extracts at $3 \mathrm{~F}$ and $5 \mathrm{~F}$, respectively (Table 2). TFC was increased from $13 \mathrm{mg} \mathrm{QE} / \mathrm{kg}$ to 16 and $19 \mathrm{mg}$ $\mathrm{QE} / \mathrm{kg}$ of quinoa extract at $3 \mathrm{~F}$ and $5 \mathrm{~F}$, respectively (Table 2). Antioxidant activity $\left(\mathrm{SC}_{50}\right)$ of quinoa extracts prepared with NF, 3F, and $5 \mathrm{~F}$ were $3.6,3.4$, and $2.3 \mathrm{mg} /$ $\mathrm{mL}$, respectively (Table 2, Additional file 1: Figure S1).

\section{Cell viability of RAW264.7 cells}

Cell viabilities of RAW 264.7, macrophages cells, are shown in Fig. 2a. Cell viabilities were reached at $100 \%$ at the concentration of $100 \mu \mathrm{g} / \mathrm{mL}$ so that the nitric oxide assay was conducted from 50,25 , and $12.5 \mu \mathrm{g} / \mathrm{mL}$ (Fig. 2a).

\section{Nitric oxide production}

Production of nitric oxide was investigated by lipopolysaccharides (LPS) stimulation. At the concentration of $50 \mu \mathrm{g} / \mathrm{mL}$, the $5 \mathrm{~F}$ extracts had significantly high antiinflammatory activities. Production of nitric oxide was decreased 22.8, 19,7 and 14.0 $\mu \mathrm{M}$ in NF, 3F, and 5F extracts, respectively (Fig. 2b). These patterns were also shown at $25 \mu \mathrm{g} / \mathrm{mL}$ as $27.4,24.5$ and $23.6 \mu \mathrm{M}$ of nitric oxide production in NF, 3F, and $5 \mathrm{~F}$ extracts, respectively. As for $12.5 \mu \mathrm{g} / \mathrm{mL}$, the nitric oxide was produced 30.8, 28.0 and $29.8 \mu \mathrm{M}$ at NF, 3F, and $5 \mathrm{~F}$ extracts, respectively. Since nitric oxide production is generated from inflammation, fermented quinoa had therapeutic abilities by reducing nitric oxide production.

\section{Discussion}

Traditionally, quinoa has been cooked in salads, soups, porridges, and stews. Quinoa are found in forms of flakes, grains, and flours and have increasingly become incorporated into products such as noodles and energy bars. Recent developments of quinoa flour in smallscale products include bread, muffins, pasta, snacks, drinks, flakes, baby foods, beer and extrudates (Diaz et al. 2013; Matsuo 2006). In order to improve the
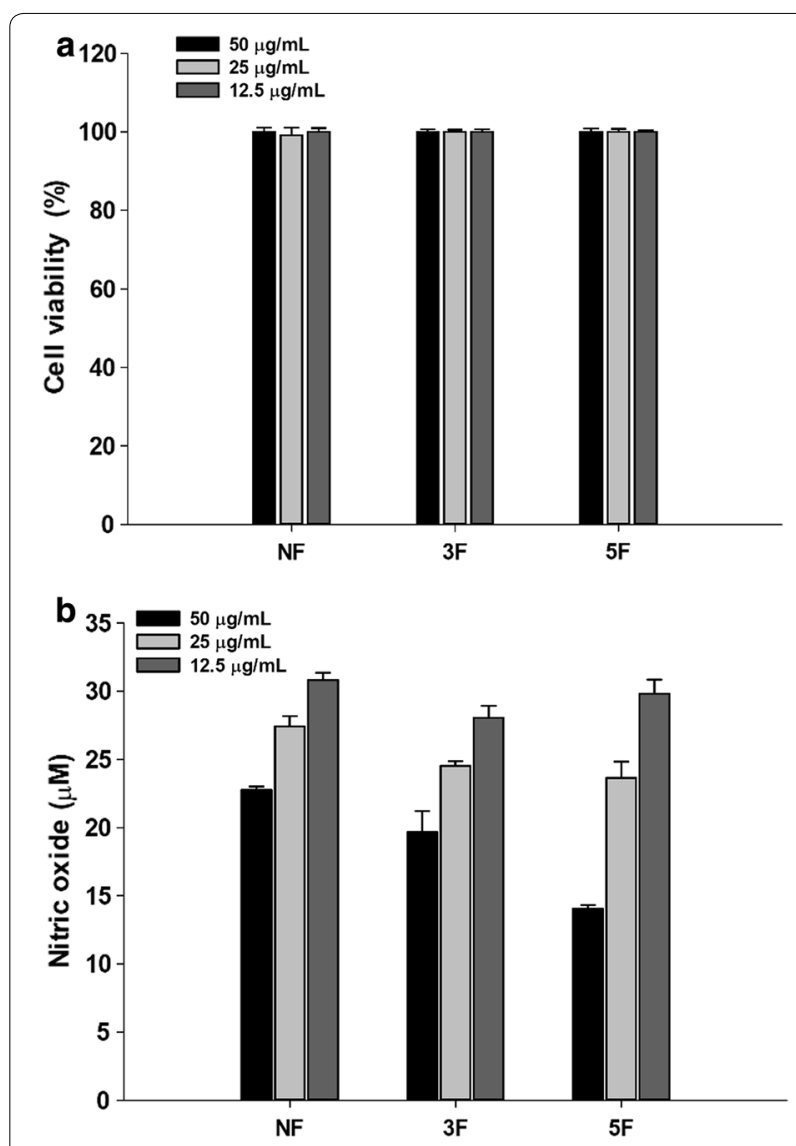

Fig. 2 Cell viability (a) and nitric oxide production (b) on RAW264.7 of quinoa and fermented quinoa extract. (NF;Non-fermented, 3F; 3 days, $5 F ; 5$ days of fermented quinoa extracts) (NF vs $3 F$ and $5 F$, $\left.{ }^{* *} \mathrm{p}<0.01\right)$

functionalities, nutrition values and taste of quinoa, we fermented quinoa grains using $R$. oligosporus. Morphological characteristics by using the SEM reveals degradation of quinoa by $R$. oligosporus enzymes after fermentation (Fig. 1a-c). Raw quinoa seeds had polygonal granules $(0.6-2.0 \mu \mathrm{m}$ diameter) present singly and as spherical aggregates (Ruales and Nair 1993). After fermentation, the polygonal granule was hardly observed and degraded into low-molecule-substances that brought different biological values to fermented

Table 2 Total phenolic and flavonoids contents and DPPH-radical scavenging activity of fermented quinoa extract

\begin{tabular}{llll}
\hline & NF & 3F & $\mathbf{5 F}$ \\
\hline Total phenolic contents $(\mathrm{mg} \mathrm{GAE} / \mathrm{kg}$ of quinoa extract) & $41 \pm 1$ & $74^{* *}$ & $80 \pm 1^{* *}$ \\
Total flavonoid contents $(\mathrm{mg}$ QE/ $/ \mathrm{kg}$ of quinoa extract) & 13 & $16^{* *}$ & $19^{* *}$ \\
DPPH radical-scavenging activity $\left(\mathrm{SC}_{50}(\mathrm{mg} / \mathrm{mL})\right.$ & 3.6 & $3.4 \pm 0.5$ & $2.3 \pm 0.1^{* *}$ \\
\hline
\end{tabular}

(NF non-fermented, $3 F 3$ days, $5 F 5$ days of fermented quinoa extracts); (NF vs $3 F$ and $5 F$, ** $p<0.01$ ) 
quinoa (Fig. 1b, c). Degradation of cell structures of fermented quinoa was due to lipases, amylases, protease, and glucoamylase that produced from $R$. oligosporus (Handoyo and Morita 2006; Jin et al. 1999). The $3 \mathrm{~F}$ and $5 \mathrm{~F}$ quinoa extracts had higher content of L-carnitine (24.1 and 11.8 times) than non-fermented quinoa. Handoyo and Morita (2006) reported that $R$. oligosporus hydrolyzed protein into amino acids and small peptides. In other study, Matsuo (2006) reported that the amount of lysine was increased from nondetection to $0.31 \mathrm{~g} / \mathrm{kg}$ dry quinoa and lysine from 0.11 to $0.51 \mathrm{~g} / \mathrm{kg}$ dry quinoa during $R$. oligosporus fermentation. L-carnitine is synthesized from lysine and methionine thus the synthesis of $\mathrm{L}$-carnitine depends on the amount of lysine and methionine in quinoa. The GABA contents in fermented quinoa showed 1.9 and 1.5 times higher than that of NF. GABA is synthesized from glutamate catalyzing by glutamate decarboxylase while quinoa contained high glutamate $(0.71 \mathrm{~g} / \mathrm{kg}$ dry quinoa) (Matsuo 2006). Fermented quinoa extract revealed $36.1 \%$ enhanced anti-oxidative activity in DPPH-radical scavenging activity level. This result was agreed with previous reported by Mastuo (2006). The enhancement of antioxidant activities probably resulted in the increased amounts of phenolic compounds by the fermentation. Contents of phenolic acids such as vanillic acids, gallic acids, chlorogenic acids, and TPC, TFC were also changed and possibly effected to improvement of DPPH-radical scavenging activity. Vanillic acid was known for main phenolic acids in quinoa, and other phenolic acids were also analyzed such as gallic acids and chlorogenic acids. Vanillic acids contents were increased by fermentation as $1.3-1.83 \mathrm{mg} / \mathrm{kg}$ by NF and $5 \mathrm{~F}$, respectively. In case of gallic acids were increased at $3 \mathrm{~F}$ by $2.37 \mathrm{mg} / \mathrm{kg}$ from $0.01 \mathrm{mg} / \mathrm{kg}$ of NF, but decreased at $5 \mathrm{~F}$ by $0.84 \mathrm{mg} /$ $\mathrm{kg}$ compared to 3F. As for chlorogenic acid, the pattern was similarly revealed as gallic acids for increased amount at 3F by $0.03 \mathrm{mg} / \mathrm{kg}$ from $0.02 \mathrm{mg} / \mathrm{kg}$ of NF, and decreased at $5 \mathrm{~F}$ as $0.02 \mathrm{mg} / \mathrm{kg}$ from $3 \mathrm{~F}$. It is probable that phenolic acids are derivatives for other phenolic acids (Rice-Evans et al. 1996). In this study, TPC (Table 2) were enhanced (1.8 and 2.0 times increase at $3 \mathrm{~F}$ and $5 \mathrm{~F}$ ) during the $R$. oligosporus fermentation and were probably obtained from formation of higher contents of phenolic compounds such as vanillic acids, gallic acids and chlorogenic acids. McCue and Shetty (2003) reported that $\alpha$-amylase and endogenous carbohydrate-cleaving enzymes activities had a role to generate polyphenols from carbohydrates-conjugated phenolic compounds. $R$. oligosporus is a known strain to produce $\beta$-glucosidase, $\beta$-glucuronidase and xylanase when degrade the cell wall matrix (Huynh et al. 2014). Thus, it was probably metabolized with the bioconversion of phenolic compounds by the fermentation leads the cell-wall degrading enzymes to hydrolysis of glycosidic bonds and produces bound phenolics and aglycone forms (Huynh et al. 2014). Also, TFC (Table 2) were enhanced by 1.2 and 1.5 times increase at $3 \mathrm{~F}$ and $5 \mathrm{~F}$. The fermentation processes releasing phenolic compounds from plant matrixes followed by the metabolic pathways of flavonoids: glycosylation, deglycosylation, ring cleavage, methylation, glucuronidation, and sulfate conjunction which are way of producing new bioactive compounds (Huynh et al. 2014). These increases in phenolic compounds effected to the enhancement of antioxidative activity (Kaur and Kapoor 2002). Increase of flavonoids contents has also influenced on DPPH-radical scavenging activity resulting in higher antioxidant activity of fermented quinoa extracts than non-fermented ones. Since antioxidant properties of fermented quinoa extracts were found, anti-inflammatory effect on mammalian cells was further investigated. Anti-inflammatory function of fermented quinoa extract was studied on RAW 264.7, macrophages, with LPS-stimulation. Nitric oxide production was inhibited $29.3 \%$ for NF, 38.9 for $3 \mathrm{~F}$ and $56.4 \%$ for $5 \mathrm{~F}$, resulting in improvement of $192.6 \%$ in anti-inflammatory activity (Fig. 2b). Kim et al. (1999) reported that the flavonoids inhibit NO production in lipopolysaccharide-activated RAW264.7 cells and reduce of iNOS enzyme expression. Thus, the increase anti-inflammatory effect of fermented quinoa compared to the regular quinoa due to increasing of total phenol and total flavonoids contents in fermented quinoa by $R$. oligosporus. Biscuits made by substituting $20 \%$ of the flour with $R$. oligosporus fermented quinoa powder increased its iron and $\alpha$-tocopherol contents by a factor more than 2.5 and scored high in sensory analysis of flavor hardness and taste in soft biscuits (Matsuo 2006). The absorption of iron from $R$. oligosporus fermented quinoa was higher than that of quinoa powder in rats for partial digestion of phosphoric compounds (Matsuo 2006). Therefore, the increased concentration of L-carnitine and GABA in fermented quinoa by $R$. oligosporus could be improved by the beneficial functionalities and nutritional values in fermented quinoa supplemented food materials.

In conclusion, fermented quinoa extract has effective antioxidant and anti-inflammatory activities. These activities may be due to presence of phenolic compounds, flavonoids and the other products produced during fermentation by $R$. oligosporus. Although the 3rd day fermentation revealed optimal conditions to produce L-carnitine and GABA, the 5-day fermented 
quinoa extract had higher TPC, TFC, antioxidant activity and improved reduction in inflammation than regular quinoa extract. In this regard, fermented quinoa can be used as a healthy and valuable food product.

\section{Additional file}

Additional file 1: Fig. S1. DPPH radical scavenging of nonfermented quinoa (NF), 3-day fermented quinoa (3F), 5-day fermented quinoa (5F).

\begin{abstract}
Abbreviations
R. oligosporus: Rhizopus oligosporus; GABA: $\gamma$-aminobutyric acid; NF: nonfermented quinoa; $3 F$ : fermented quinoa at 3 days; $5 \mathrm{~F}$ : fermented quinoa at 5 days; GAE: gallic acid equivalent; QE: quercetin equivalent; PDA: potato dextrose agar; SEM: scanning electron microscope; DMSO: dimethyl sulfoxide; LC/MS: liquid chromatography-mass spectrometry; TPC: total phenolic content; TFC: total flavonoid content; DPPH: 2,2-diphenyl-1-picryhydrazyl; DMEM: Dulbecco's modified Eagle's medium.
\end{abstract}

\section{Authors' contributions}

DK designed and coordinated the study. JH performed fermentation and morphological characterization. NP and JK performed preparation of extracts and component analyses. TN carried out antioxidant assay and cell test. JH and TN drafted manuscript. All authors read and approved the final manuscript.

\section{Author details}

${ }^{1}$ Graduate School of International Agricultural Technology, Seoul National University, Pyeongchang 25354, Republic of Korea. ${ }^{2}$ Institutes of Food Industrialization, Institutes of Green Bio Science \& Biotechnology, Seoul National University, Pyeongchang 25354, Republic of Korea. ${ }^{3}$ Center for Food and Bioconvergence, Seoul National University, Seoul 08826, Republic of Korea.

\section{Acknowledgements}

Not applicable.

\section{Competing interests}

The authors declare that they have no competing interests.

\section{Availability of data and materials}

All data generated or analyzed during this study are included in this manuscript and Additional material.

\section{Consent for publication}

Not applicable.

\section{Ethics approval and consent to participate}

Not applicable. This paper does not contain any studies with human participants or animal performed by any of the authors.

\section{Funding}

This work was partially supported by the Basic Science Research Program through the National Research Foundation of Korea (NRF) funded by the Ministry of Education (NRF-2015R1D1A1A01056929; D. Kim, and 2018R1D1A1B07049569; T.T. Hanh Nguyen), by Korea Institute of Planning and Evaluation for Technology in Food, Agriculture, Forestry (IPET) through Agriculture, Food and Rural Affairs Research Center Support Program, funded by Ministry of Agriculture, Food and Rural Affairs (MAFRA) (710012031HD220), and under the framework of International Cooperation Program managed by the NRF (2016K1A3A1A19945059), and OTTOGI Corporation through Research and Publication Project.

\section{Publisher's Note}

Springer Nature remains neutral with regard to jurisdictional claims in published maps and institutional affiliations.
Received: 19 June 2018 Accepted: 3 September 2018

Published online: 10 September 2018

\section{References}

Bremer J (1983) Carnitine-metabolism and functions. Physiol Rev $63: 1420-1480$

Brown GC (1999) Nitric oxide and mitochondrial respiration. Biochim Biophys Acta 1411:351-369

Carciochi RA, Galván-D'Alessandro L, Vandendriessche P, Chollet S (2016) Effect of germination and fermentation process on the antioxidant compounds of quinoa seeds. Plant Foods Hum Nutr 71:361-367

Chang CC, Yang MH, Wen HM, Chern JC (2002) Estimation of total flavonoid content in propolis by two complementary colorimetric methods. J Food Drug Anal 10:178-182

Choi ES, Kang YY, Mok H (2018a) Evaluation of the enhanced antioxidant activity of curcumin within exosomes by Fluorescence monitoring. Biotechnol Bioproc Eng 23:150-157

Choi MH, Jo HG, Kim MJ, Kang MJ, Shin HJ (2018b) Fruit juice supplementation alters human skin antioxidant levels in vivo: case study of Korean adults by resonance raman spectroscopy. Biotechnol Bioproc Eng 23:116-121

deReu JC, Linssen VAJM, Rombouts FM, Nout MJR (1997) Consistency, polysaccharidase activities and non-starch polysaccharides content of soya beans during tempe fermentation. J Sci Food Agric 73:357-363

Dhakal R, Bajpai VK, Baek K-H (2012) Production of GABA ( $\gamma$-aminobutyric acid) by microorganisms: a review. Braz J Microbiol 43:1230-1241

Diaz JMR, Kirjoranta S, Tenitz S, Penttila PA, Serimaa R, Lampi AM, Jouppila K (2013) Use of amaranth, quinoa and kaniwa in extruded corn-based snacks. J Cereal Sci 58:59-67

Handoyo T, Morita N (2006) Structural and functional properties of fermented soybean (Tempeh) by using Rhizopus oligosporus. Int J Food Prop 9:347-355

Huynh NT, Van Camp J, Smagghe G, Raes K (2014) Improved release and metabolism of flavonoids by steered fermentation processes: a review. Int J Mol Sci 15:19369-19388

Jin B, van Leeuwen HJ, Patel B, Doelle HW, Yu Q (1999) Production of fungal protein and glucoamylase by Rhizopus oligosporus from starch processing wastewater. Process Biochem 34:59-65

Kalaiselvi T, Panneerselvam C (1998) Effect of L-carnitine on the status of lipid peroxidation and antioxidants in aging rats. J Nutr Biochem 9:575-581

Kaur C, Kapoor HC (2002) Anti-oxidant activity and total phenolic content of some Asian vegetables. Int J Food Sci Tech 37:153-161

Kim HK, Cheon BS, Kim YH, Kim SY, Kim HP (1999) Effects of naturally occurring flavonoids on nitric oxide production in the macrophage cell line RAW 264.7 and their structure-activity relationships. Biochem Pharmacol 58:759-765

Koeth RA, Wang Z, Levison BS, Buffa JA, Org E, Sheehy BT, Britt EB, Fu X, Wu Y, Li $L$ (2013) Intestinal microbiota metabolism of L-carnitine, a nutrient in red meat, promotes atherosclerosis. Nat Med 19:576-585

Masayo A, Watanabe K (2010) Functional and bioactive properties of quinoa and amaranth. Food Sci Technol Res 16:163-168

Matsuo M (2005) In vivo antioxidant activity of methanol extract from quinoa fermented with Rhizopus oligosporus. J Nutr Sci Vitaminol 51:449-452

Matsuo M (2006) Suitability of quinoa fermented with Rhizopus oligosporus as an ingredient of biscuit. J Jpn Soc Food Sci 53:62-69

Maxwell T, Lee KS, Chun SY, Nam KS (2017) Mineral-balanced deep sea water enhances the inhibitory effects of chitosan oligosaccharide on atopic dermatitis-like inflammatory response. Biotechnol Bioproc Eng 22:120-128

McCue P, Shetty K (2003) Role of carbohydrate-cleaving enzymes in phenolic antioxidant mobilization from whole soybean fermented with Rhizopus oligosporus. Food Biotechnol 17:27-37

Nguyen TTH, Yu S-H, Kim J, An E, Hwang K, Park J-S, Kim D (2015) Enhancement of quercetin water solubility with steviol glucosides and the studies of biological properties. Funct Foods Health Dis 5:437-449

Park N, Lee TK, Nguyen TTH, An EB, Kim NM, You YH, Park TS, Kim D (2016) The effect of fermented buckwheat on producing L-carnitine and Gammaaminobutyric acid (GABA) enriched designer eggs. J Sci Food Agric 97:2891-2897 
Rice-Evans CA, Miller NJ, Paganga G (1996) Structure-antioxidant activity relationships of flavonoids and phenolic acids. Free Radic Biol Med 20:933-956

Ruales J, Nair BM (1993) Content of fat, vitamins and minerals in quinoa (Chenopodium quinoa, Willd) seeds. Food Chem 48:131-136
Steiber A, Kerner J, Hoppel CL (2004) Carnitine: a nutritional, biosynthetic, and functional perspective. Mol Aspects Med 25:455-473

Vega-Gálvez A, Miranda M, Vergara J, Uribe E, Puente L, Martínez EA (2010)

Nutrition facts and functional potential of quinoa (Chenopodium quinoa willd.), an ancient Andean grain: a review. J Sci Food Agric 90:2541-2547
Submit your manuscript to a SpringerOpen ${ }^{\circ}$ journal and benefit from:

- Convenient online submission

- Rigorous peer review

- Open access: articles freely available online

- High visibility within the field

- Retaining the copyright to your article

Submit your next manuscript at $\boldsymbol{\nabla}$ springeropen.com 